\title{
Driver's License
}

National Cancer Institute

\section{Source}

National Cancer Institute. Driver's License. NCI Thesaurus. Code C122899.

A document that authorizes a person to operate a motor vehicle on public roads. 